\title{
Avaliação de uma Equação de Predição das Exigências Protéicas para Aves Reprodutoras Pesadas na Fase de Produção ${ }^{1}$
}

\author{
Carlos Bôa-Viagem Rabello², Nilva Kazue Sakomura ${ }^{3}$, Flavio Alves Longo ${ }^{4}$, Otto Mack Junqueira ${ }^{3}$, \\ Carlos Roberto Pacheco ${ }^{5}$
}

RESUMO - O objetivo do presente trabalho foi avaliar uma equação de predição das exigências de proteína bruta (PB) para reprodutoras pesadas na fase de produção. O experimento foi realizado com 600 aves reprodutoras pesadas, Hubbard HI-Y, durante o período de 31 a 46 semanas de idade, alojadas em boxes num delineamento experimental inteiramente casualizado com três tratamentos e cinco repetições de 40 aves. Os tratamentos consistiram de: T1 - Fornecimento de PB de acordo com o manual da linhagem (controle), T2- Fornecimento de PB de acordo com a equação de predição determinada, utilizando os dados de desempenho médio das aves do tratamento controle para predizer as exigências e T3- Fornecimento de PB de acordo com a equação de predição determinada, utilizando os dados de desempenho de cada parcela experimental para predizer as exigências, onde a equação de predição avaliada foi: $\mathrm{PB}=2,282 . \mathrm{P}^{0,75}+0,356 . \mathrm{G}+0,262 . \mathrm{MO}$, sendo $\mathrm{PB}$ a exigência de proteína bruta (g/ave/dia), $\mathrm{P}$ o peso corporal $(\mathrm{kg}), \mathrm{G}$ o ganho de peso $(\mathrm{g})$ e MO a massa de ovos $(\mathrm{g})$. As rações foram formuladas para atender as exigências nutricionais e quando necessário eram incluídos os aminoácidos sintéticos, metionina, lisina, triptofano, treonina e arginina. As aves alimentadas de acordo com a equação ingeriram menores quantidades de proteína (20,8g/dia) quando comparadas às alimentadas de acordo com as recomendações $(23,80 \mathrm{~g})$, entretanto isto levou a menores pesos dos ovos refletindo no peso dos pintos. A equação de predição proporcionou melhores resultados quanto à eficiência protéica. Assim, concluiu-se que a equação de predição não forneceu a quantidade mínima de proteína bruta para atender as exigências dos aminoácidos não suplementados na dieta.

Palavras-chave: equação de predição, exigência de proteína, reprodutoras pesadas

\section{Evaluation of a Prediction Equation of Crude Protein for Broiler Breeder Hens}

\begin{abstract}
The objective of this study was to evaluated a crude protein requirement equation elaborated for broiler breeders. The experiment was conducted with 60031 -weeks old Hubbard HI-Y broiler breeders in a completely randomized experiment with three treatments and five replications. The treatments were: T1-Crude protein supply according to lineage recommendation manual (control), T2 - Crude protein supply according to a prediction equation adjusted in function of the performance data of the standard treatment, and $\mathrm{T} 3$ - Crude protein supply according to the prediction equation adjusted in function of the performance data of each experimental unit. The prediction equation was : $\mathrm{CP}=2.282 \mathrm{~W}^{0,75}+0.356 \mathrm{G}+0.262 \mathrm{EM}$, where $\mathrm{CP}$ is crude protein requirement $(\mathrm{g} / \mathrm{bird} / \mathrm{day}), \mathrm{W}$ is body weight $(\mathrm{kg}), \mathrm{G}$ is weight gain (g/day) and EM is egg mass (g/day). Birds feed according to the equation had lower protein intake ( $20.8 \mathrm{~g}$ /day) compared to those of the standard treatment $(23.8 \mathrm{~g}$ /day), this leading to lower weight which reflected in chick weight. Feeding according to the equation provided better results as concerned to protein efficiency. It was concluded that the protein levels recommended through the equation were not sufficient for providing minimum protein requirements for broiler breeders.
\end{abstract}

Key Words: broiler breeders, prediction equation, protein requirements

\section{Introdução}

As exigências de proteína para matrizes pesadas na fase de produção variam de $18 \mathrm{~g}$ a $23 \mathrm{~g} /$ ave/dia (Waldroup et al., 1976; Bornstein et al., 1979; Pearson \& Herron, 1981, 1982; Wilson \& Harms, 1984; Spratt \& Leeson, 1987; Couto, 1988; Scholoffel et al., 1988; NRC, 1994; Lopez \& Leeson, 1995a).
$\mathrm{Na}$ prática, as recomendações de proteína para reprodutoras pesadas são relativamente altas, recomendando-se formular rações com $16 \%$ de proteína bruta, levando uma ave no pico de postura a consumir em torno de $26 \mathrm{~g}$ de proteína/dia (Lopez \& Leeson, 1995a). Alguns trabalhos têm mostrado que o excesso no consumo de proteína pode provocar efeitos negativos na eclosão de ovos (Pearson \& Herron, 1982; Spratt \&

\footnotetext{
${ }^{1}$ Parte da Tese de Doutorado do primeiro autor, apresentada à FCAV-UNESP - Jaboticabal, São Paulo. Pesquisa financiada pela FAPESP 2 Prof. Dr. do Dep. de Zootecnia, UFRPE, R. Dom Manoel de Medeiros, s/n, Dois Irmãos, Recife, PE. CEP:52.171-900.E.mail: cbviagem@bol.com.br 3 Prof. Dr. do Dep. de Zootecnia, UNESP, Jaboticabal, SP. E.mail: sakomura@fcav.unesp.br

${ }^{4}$ Estudante de Pós-graduação da UNESP, Jaboticabal, SP

5 CNA - Consultoria em Nutrição Animal.
} 
Leeson, 1987; Lopez \& Leeson, 1995a), principalmente pelo aumento no ganho de peso das aves dificultando muitas vezes a cópula.

Alguns fatores influenciam as exigências de proteína e muitas vezes não são considerados para estabelecer as quantidades a serem fornecidas. Hurwitz \& Bornstein (1973) afirmaram que a forma mais precisa para estabelecer as exigências protéicas se baseia no método fatorial, o qual consiste em determinar as necessidades de proteína considerando a soma das necessidades para manutenção, crescimento e produção.

Sabendo-se que o ponto crítico na produção avícola são os gastos com a alimentação e que a sua otimização levará a retornos econômicos mais satisfatórios, modelos vêm sendo desenvolvidos para estabelecer os programas de alimentação e contribuir para atingir tal finalidade.

Portanto, este trabalho teve como objetivo avaliar uma equação de predição das exigências protéicas para aves reprodutoras pesadas, desenvolvida na Faculdade de Ciências Agrárias da Universidade Estadual Paulista, Câmpus de Jaboticabal.

\section{Material e Métodos}

O experimento foi realizado no Setor de Avicultura do Departamento de Zootecnia da Faculdade de Ciências Agrárias e Veterinárias, Câmpus de Jaboticabal, Jaboticabal, São Paulo.

Foi realizado um experimento utilizando 600 aves reprodutoras de corte, fêmeas, Hubbard HI-Y e 60 machos Peterson, durante o período de 31 a 46 semanas de idade. O experimento foi conduzido durante 112 dias, sendo quatro ciclos de 28 dias. As aves foram alojadas em um aviário experimental com boxes medindo 3,90 x 3,35 m de acordo com um delineamento experimental inteiramente casualizado, com três tratamentos e cinco repetições de 40 fêmeas e quatro machos.

Os boxes foram equipados com quatro comedouros pendulares (equipado com grade exclusora de machos) para as fêmeas e um para os machos. Os comedouros dos machos foram instalados a uma altura de 50 a $60 \mathrm{~cm}$, dependendo do comportamento das aves, evitando ingestão de ração pelas fêmeas. Nos boxes foram instalados também dois bebedouros pendulares e dois ninhos com seis bocas cada.

A ração foi fornecida separadamente, sendo uma ração específica para os machos e uma para as fêmeas.
Os tratamentos consistiram de:

T1- Fornecimento de proteína bruta (PB) de acordo com o manual da linhagem (controle);

T2- Fornecimento de PB de acordo com a equação de predição determinada por Rabello (2001), sendo que para calcular as estimativas semanais das exigências de PB através da equação foram utilizados os dados de desempenho médio das aves do tratamento controle (peso corporal, ganho de peso e produção de massa de ovos); e

T3- Fornecimento de proteína bruta (PB) de acordo com a equação de predição determinada por Rabello (2001), sendo que foram utilizados os dados de desempenho de cada uma das respectivas parcelas experimentais desse tratamento.

A equação avaliada foi desenvolvida na Universidade Estadual Paulista, Campus de Jaboticabal: $\mathrm{PB}=2,282 . \mathrm{P0} 0,75+0,356 . \mathrm{G}+0,262 . \mathrm{MO}$ (Rabello, 2001), em que $\mathrm{PB}$ é a exigência de proteína bruta (g/ave/ dia), P o peso corporal médio ( $\mathrm{kg}$ ), G o ganho de peso (g/dia) e MO a massa de ovos (g/dia).

Os dados de peso corporal médio, ganho de peso e produção de ovos foram aplicados na equação semanalmente para estimar as exigências de PB (Tratamentos T2 e T3). As quantidades de proteína bruta a serem fornecidas foram calculadas semanalmente a partir de estimativas de ganho de peso e produção da massa de ovos. Portanto, amostras composta de 10 aves de cada parcela experimental foram pesadas e os ovos pesados duas vezes por semana.

$\mathrm{O}$ arraçoamento das aves foi realizado diariamente e de forma controlada de acordo com cada tratamento, entretanto, mantendo a mesma ingestão dos nutrientes exceto da proteína bruta. Assim, semanalmente foram formuladas diferentes dietas com os mesmos níveis nutricionais com exceção do nível protéico, possibilitando assim promover a mesma ingestão dos demais nutrientes exceto da proteína, sendo esta de acordo com cada tratamento. As dietas experimentais foram formuladas para atender as necessidades nutricionais das aves segundo as recomendações do manual da linhagem (Tabela 1).

Nas dietas com níveis mais baixos de proteína foram utilizados alguns aminoácidos sintéticos como: metionina, lisina, treonina, triptofano e arginina, com o objetivo de fornecer as mesmas quantidades que a ração testemunha.

As aves receberam 17 horas de luz diária. A iluminação natural foi complementada com luz artificial controlada por relógio automático (Timer). 
Tabela 1 - Composição percentual da dieta do tratamento testemunha e os níveis nutricionais utilizados nas rações

Table 1 - Percentage composition of the experimental diet for the standard treatment and nutritional levels used in the rations

\begin{tabular}{|c|c|}
\hline $\begin{array}{l}\text { Ingredientes } \\
\text { Ingredients }\end{array}$ & $\begin{array}{c}\text { Composição percentual (\%) } \\
\text { Percentage composition }\end{array}$ \\
\hline Milho & 64,841 \\
\hline Corn & \\
\hline Farelo de soja & 18,455 \\
\hline $\begin{array}{l}\text { Soybean meal } \\
\text { Farelo de trigo }\end{array}$ & 5,000 \\
\hline $\begin{array}{l}\text { Wheat meal } \\
\text { Óleo vegetal }\end{array}$ & 1,519 \\
\hline $\begin{array}{l}\text { Soybean oil } \\
\text { Calcário }\end{array}$ & 7,419 \\
\hline Limestone & \\
\hline $\begin{array}{l}\text { Fosfato bicálcico } \\
\text { Dicalcium phosphate }\end{array}$ & 1,694 \\
\hline DL-Metionina 99 & 0,217 \\
\hline Dl-methionine 99 & \\
\hline $\begin{array}{l}\mathrm{L}-\text { Lisina } \mathrm{HCl} \\
\mathrm{HCl} \text { L-lysine }\end{array}$ & 0,064 \\
\hline $\begin{array}{l}\text { Cloreto de colina }(60 \%) \\
\text { Choline chloride } 60 \%\end{array}$ & 0,035 \\
\hline Suplemento vitamínico ${ }^{(1)}$ & 0,300 \\
\hline $\begin{array}{l}\text { Vitamin mix } \\
\text { Suplemento mineral } \\
(1)\end{array}$ & 0,160 \\
\hline Mineral mix & \\
\hline $\begin{array}{l}\text { Sal comum } \\
\text { Salt }\end{array}$ & 0,296 \\
\hline $\begin{array}{l}\text { Composição calculada } \\
\text { Calculated composition }\end{array}$ & - \\
\hline $\begin{array}{l}\text { Proteína bruta, } \% \\
\text { Crude protein }\end{array}$ & 15,000 \\
\hline Energia Metabolizável, kcal/kg & 2.870 \\
\hline Metabolizable energy & \\
\hline $\begin{array}{l}\text { Metionina, \% } \\
\text { Methionine }\end{array}$ & 0,460 \\
\hline $\begin{array}{l}\text { Metionina }+ \text { Cistina, } \% \\
\text { Methionine }+ \text { cistine }\end{array}$ & 0,720 \\
\hline Lisina, $\%$ & 0,758 \\
\hline Lysine & \\
\hline Triptofano, $\%{ }^{(2)}$ & 0,172 \\
\hline Thryptophan & \\
\hline Treonina, $\%(2)$ & 0,510 \\
\hline Threonine & \\
\hline $\begin{array}{l}\text { Arginina, } \%(2) \\
\text { Arginine }\end{array}$ & 0,872 \\
\hline $\begin{array}{l}\text { Cálcio, } \% \\
\text { Calcium }\end{array}$ & 3,300 \\
\hline $\begin{array}{l}\text { Fósforo disponível, \% } \\
\text { Available phosphorus }\end{array}$ & 0,420 \\
\hline
\end{tabular}

1 Os suplementos vitaminico e mineral foram formulados para atender as exigências nutricionais das aves e produzidos pela Granja Rezende (Vitamin and mineral mix were formulated to meet the nutritional requirements of broiler breeders and were produced at Granja Rezende).

${ }^{2}$ Quantidade mínima fornecida (Minimum intake). 
Nas Tabelas 2 e 3 estão apresentados os registros de temperatura e umidade, respectivamente, obtidos através de termo-higrógrafo durante todo o período experimental.

Os parâmetros de desempenho avaliados foram: peso corporal $(\mathrm{kg})$, consumo de proteína por dia e acumulado $(\mathrm{g})$, conversão alimentar (g:g), eficiência protéica (g:g), produção de ovos (\%), peso dos ovos (g) e massa de ovos (g).

Foram realizadas duas incubações de ovos às 35 e 42 semanas de idade das aves. Foram coletados em torno de 200 ovos de cada parcela experimental representando cada incubação às 35 e 36 semanas e às 42 e 43 semanas de idade. Os ovos foram desinfetados logo após a coleta, em seguida armazenados durante o período de 3 dias em sala climatizada e incubados. Para incubação dos ovos foram utilizadas máquinas incubadoras e nascedouros da marca Rooster Ltda. com capacidades para 8.400 ovos.

Foram avaliados eclosão, eclodibilidade e fertilidade dos ovos (\%) e peso dos pintos (g).

No final do período experimental, retiraram-se duas aves com peso médio de cada parcela experimental, que após de abatidas por deslocamento cervical foram depenadas e congeladas. Posteriormente, as carcaças foram serradas e moídas para análises de composição química corporal (água, proteína, gordura e cinzas) segundo metodologia descrita pela AOAC (1990).

As análises estatísticas dos parâmetros avaliados foram realizadas pelo programa computacional SAS for Windows v. 6.12 (1996). As análises foram realizadas através de contrastes ortogonais.

Tabela 2 - Médias de temperatura ambiente durante o período experimental

Table 2 - Environment temperature means in the experimental period

\begin{tabular}{|c|c|c|c|c|c|c|}
\hline \multirow[t]{2}{*}{$\begin{array}{l}\text { Períodos } \\
\text { Periods }\end{array}$} & \multirow[t]{2}{*}{$\begin{array}{l}\text { Idade (semanas) } \\
\text { Age (Weeks) }\end{array}$} & \multicolumn{5}{|c|}{$\begin{array}{c}\text { Temperatura }\left({ }^{0} \mathrm{C}\right) \\
\text { Temperature }\end{array}$} \\
\hline & & $\begin{array}{l}\text { Máxima } \\
\text { Maximum }\end{array}$ & $\begin{array}{l}\text { Mínima } \\
\text { Minimum }\end{array}$ & $\begin{array}{c}\text { Às 9:00 horas } \\
\text { 9:00 a.m. }\end{array}$ & $\begin{array}{c}\text { Às 21:00 horas } \\
\text { 21:00 p.m. }\end{array}$ & $\begin{array}{l}\text { Médias } \\
\text { Means }\end{array}$ \\
\hline 1 & $31-34$ & 27,64 & 17,79 & 20,20 & 22,89 & 22,28 \\
\hline 2 & $35-38$ & 29,20 & 18,93 & 22,36 & 23,09 & 23,33 \\
\hline 3 & $39-42$ & 29,20 & 21,48 & 23,64 & 23,66 & 24,33 \\
\hline 4 & $43-46$ & 29,63 & 20,64 & 22,61 & 24,20 & 24,26 \\
\hline $\begin{array}{l}\text { Média } \\
\text { Mean }\end{array}$ & & 28,92 & 19,71 & 22,20 & 23,46 & 23,55 \\
\hline
\end{tabular}

Tabela 3 - Médias da umidade relativa do ar durante o período experimental

Table 3 - Relative humidity means during the experimental period

\begin{tabular}{lcccc}
\hline $\begin{array}{l}\text { Períodos } \begin{array}{c}\text { Idade } \\
\text { Periods }\end{array} \\
\text { (semanas) } \\
\text { Age (weeks) }\end{array}$ & \multicolumn{3}{c}{$\begin{array}{c}\text { Umidade (\%) } \\
\text { Humidity }\end{array}$} \\
\cline { 3 - 5 } & & $\begin{array}{c}\text { Máxima } \\
\text { Maximum }\end{array}$ & $\begin{array}{c}\text { Mínima } \\
\text { Minimum }\end{array}$ & $\begin{array}{c}\text { Médias } \\
\text { Means }\end{array}$ \\
\hline 1 & $31-34$ & 93,48 & 43,40 & 68,44 \\
2 & $35-38$ & 93,61 & 40,86 & 67,23 \\
3 & $39-42$ & 84,50 & 52,82 & 68,66 \\
4 & $43-46$ & 87,29 & 48,08 & 67,68 \\
Média & & 89,72 & 46,29 & 68,00 \\
Means & & & &
\end{tabular}

\section{Resultados e Discussão}

Na Tabela 4 estão apresentados os consumos diário e acumulado de proteína pelas aves durante cada período experimental. Como pode ser observado, a equação de predição das exigências protéicas proporcionou menores ingestões de proteína quando comparados com o tratamento controle.

Verifica-se que houve diferenças no consumo de proteína entre os dois tratamento em que se utilizou a equação de predição para estimar as exigências protéicas (T2 e T3) durante todo o período experi- 
Tabela 4 - Médias do consumo de proteína diário (g/ave/dia) e acumulado (g/aves/período) durante cada período experimental

Table 4 - Means of daily protein (g/bird/day) and total protein intake (g/bird/period) during the entire production period

\begin{tabular}{|c|c|c|c|c|c|}
\hline \multirow[t]{2}{*}{$\begin{array}{l}\text { Tratamentos } \\
\text { Treatment }\end{array}$} & \multicolumn{5}{|c|}{$\begin{array}{l}\text { Períodos (semanas) } \\
\text { Periods (weeks) }\end{array}$} \\
\hline & $(31-34)$ & $(35-38)$ & $(39-42)$ & $(43-46)$ & $(31-46)$ \\
\hline & \multicolumn{5}{|c|}{$\begin{array}{l}\text { Consumo diário (g/ave/dia) } \\
\text { Daily intake (g/bird/day) }\end{array}$} \\
\hline $\mathrm{T} 1$ & 23,94 & 23,94 & 23,86 & 23,47 & 23,80 \\
\hline $\mathrm{T} 2$ & 21,47 & 21,19 & 20,78 & 20,11 & 20,89 \\
\hline $\mathrm{T} 3$ & 21,67 & 20,96 & 20,29 & 19,94 & 20,71 \\
\hline $\mathrm{F}$ & $146,63^{* *}$ & $900,26 * *$ & $504,79 * *$ & $1088,8 * *$ & $1390,77^{* *}$ \\
\hline $\mathrm{T} 1$ vs $\mathrm{T} 2$ e $\mathrm{T} 3$ & $291,66^{* *}$ & $1791,56 * *$ & $993,64 * *$ & $2157,19 * *$ & $2774,21 * *$ \\
\hline $\mathrm{T} 2 \mathrm{vs} \mathrm{T} 3$ & $1,59 \mathrm{NS}$ & $8,95 *$ & $15,94 * *$ & $4,12 \mathrm{NS}$ & $7,33^{*}$ \\
\hline \multirow[t]{2}{*}{ CV $(\%)$} & 1,13 & 0,56 & 0,89 & 0,64 & 0,48 \\
\hline & \multicolumn{5}{|c|}{$\begin{array}{c}\text { Consumo acumulado (g/ave/período) } \\
\text { Total intake (g/bird/day) }\end{array}$} \\
\hline $\mathrm{T} 1$ & 670,24 & 670,77 & 668,05 & 657,08 & $2.665,60$ \\
\hline $\mathrm{T} 2$ & 601,23 & 593,39 & 581,77 & 563,08 & $2.339,47$ \\
\hline $\mathrm{T} 3$ & 606,83 & 586,76 & 568,16 & 558,18 & $2.294,38$ \\
\hline $\mathrm{F}$ & $145,56^{* *}$ & $897,39 * *$ & $503,87 * *$ & $1089,1 * *$ & $1368,09 * *$ \\
\hline $\mathrm{T} 1$ vs $\mathrm{T} 2$ e $\mathrm{T} 3$ & 289,57 & $1785,62 * *$ & $991,85^{* *}$ & $2174,30 * *$ & $2729,25 * *$ \\
\hline $\mathrm{T} 2$ vs T3 & $1,55 \mathrm{NS}$ & $9,15^{*}$ & $15,90 * *$ & $4,21 \mathrm{NS}$ & $6,93 *$ \\
\hline $\mathrm{CV}(\%)$ & 1,13 & 0,56 & 0,89 & 0,64 & 0,48 \\
\hline
\end{tabular}

NS = não significativo, ${ }^{*}=$ significativo $\mathrm{P}<0,05,{ }^{* *}=$ significativo $\mathrm{P}<0,01$.

$N S=$ not significant,${ }^{*}=$ significant $P<.05,{ }^{* *}=$ significant $P<.01$.

mental, sendo que no primeiro e quarto períodos não foram encontradas diferenças significativas. No entanto, esse resultado não levou a diferenças no desempenho produtivo e reprodutivo entre esses tratamentos.

Segundo Leeson \& Summers (2000), as exigências de proteína e aminoácidos não tem sido claramente estabelecidas e as aves estão sendo alimentadas com excesso de proteína de 23 a $25 \mathrm{~g} / \mathrm{ave} / \mathrm{dia}$ na fase de produção.

Observa-se na Tabela 5 que a maior parte da proteína ingerida, em torno de $66 \%$, foi destinada à produção de ovos, $29 \%$ destinada para mantença e $4 \%$ para o ganho de peso. Diferentes estimativas são apresentadas por Leeson \& Summers (2000), onde reprodutoras pesadas às 32 semanas de idade devem consumir um total de $21 \mathrm{~g}$ de $\mathrm{PB} / \mathrm{dia}$, sendo $1 \mathrm{~g}$ para o crescimento $(4,67 \%), 10 \mathrm{~g}$ para produção de ovos $(47,62 \%)$ e $10 \mathrm{~g}$ para mantença $(47,62 \%)$ e para aves às 55 semanas de idade um total de $19 \mathrm{~g}$ de $\mathrm{PB} /$ dia, sendo $8 \mathrm{~g}$ para produção de ovos $(42,10 \%)$ e $11 \mathrm{~g}$ para mantença $(57,80 \%)$.

Santomá (1991) comenta que as exigências de nitrogênio são variáveis em função do peso corporal. Segundo Scott et al. (1982), Hurwitz \& Bornstein
(1973) e INRA (1984), as exigências de nitrogênio para mantença estão ao redor de 25 a $30 \%$ da exigência total, similar ao encontrado neste trabalho (29\%).

Verifica-se que os menores consumos de proteína proporcionados pela equação de predição não influenciaram a produção de ovos (Tabela 6). Resultados similares foram encontrados por Lopez \& Leeson (1995a), quando no mesmo período forneceram $16,19,22,5$ e $25,5 \mathrm{~g}$ de proteína, entretanto as aves que consumiram $16 \mathrm{~g}$ tiveram um menor pico de postura, tendo sido observado maior persistência na postura levando à mesma produção de ovos no final da vida produtiva, quando comparadas as aves que consumiram 25,5 g de proteína.

Quanto ao peso dos ovos foram encontradas diferenças significativas a partir do segundo período de produção, em que as menores ingestões de proteína proporcionaram diminuição de $1,5 \%$ no peso dos ovos quando comparado ao tratamento controle. Entretanto, não houve redução significativa na produção da massa de ovos (Tabela 6). Estas diferenças foram mais acentuadas no terceiro e quarto períodos de produção, caracterizados pela fase de pico na produção de massa de ovos.

Couto (1988), ao fornecer 18, 20, 22 e $24 \mathrm{~g}$ de 
Tabela 5 - Médias do consumo de proteína total e fracionada para diferentes funções durante o período experimental dos tratamentos T2 e T3

Table 5 - Total and partition protein intake means for the different functions during the experimental period for treatment T2 and T3

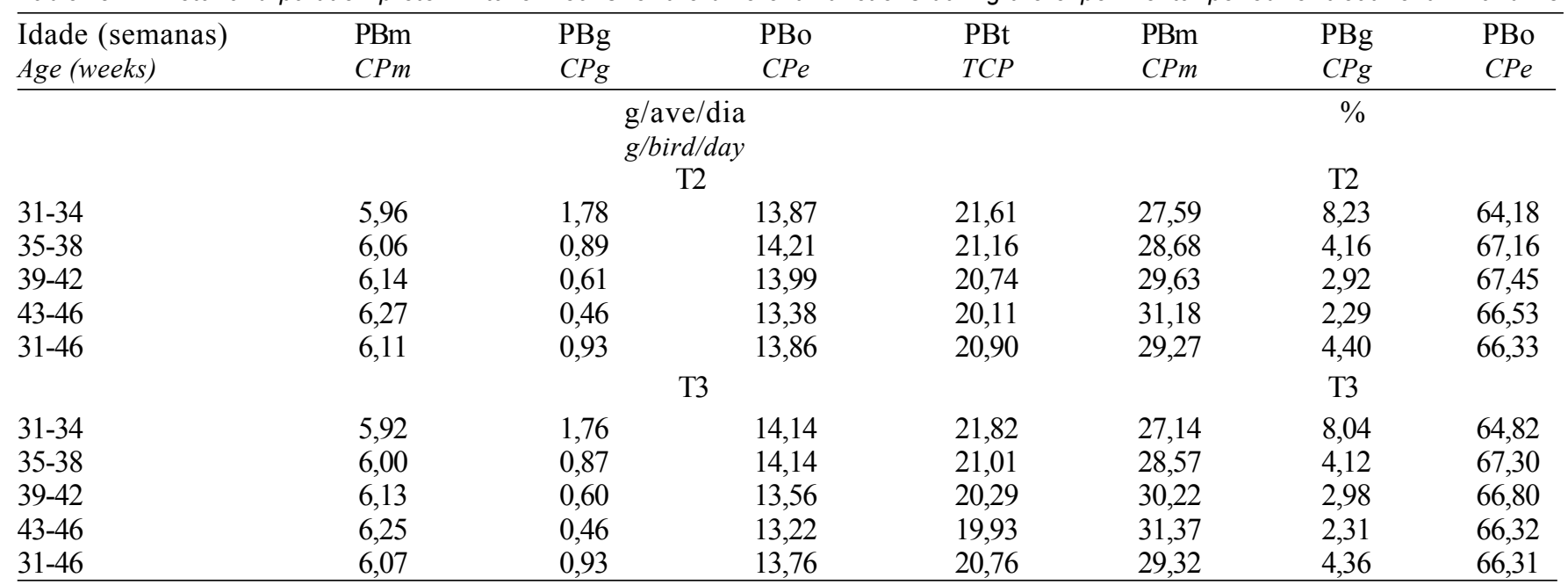

${ }_{1} \mathrm{PBm}=$ proteína bruta para mantença $(\mathrm{CPm}=$ crude protein for maitenance).

$2 \mathrm{PBg}=$ proteína bruta para o ganho de peso (CPg = crude protein for weight gain).

3 PBo = proteína bruta para produção de ovos $(C P e=$ crude protein for egg production $)$.

${ }^{4} \mathrm{PBt}=$ proteína bruta total $(T C P=$ total crude protein $)$.

Tabela 6 - Médias da produção de ovos (\%), peso dos ovos (g) e produção de massa de ovos (g) durante cada período de produção

Table 6 - Means of egg production (\%), egg weight $(g)$ and mass egg production (g) during each production period

\begin{tabular}{|c|c|c|c|c|c|}
\hline \multirow[t]{2}{*}{$\begin{array}{l}\text { Tratamentos } \\
\text { Treatments }\end{array}$} & \multicolumn{5}{|c|}{ Períodos (semanas) } \\
\hline & $(31-34)$ & $(35-38)$ & $(39-42)$ & $(43-46)$ & $(31-46)$ \\
\hline & \multicolumn{5}{|c|}{$\begin{array}{l}\text { Produção de ovos (\%) } \\
\text { Egg production }\end{array}$} \\
\hline $\mathrm{T} 1$ & 85,99 & 86,15 & 83,02 & 78,05 & 83,30 \\
\hline $\mathrm{T} 2$ & 86,19 & 86,47 & 81,96 & 76,97 & 82,90 \\
\hline $\mathrm{T} 3$ & 87,84 & 87,02 & 81,49 & 79,18 & 83,88 \\
\hline $\mathrm{F}$ & $0,65 \mathrm{NS}$ & $0,13 \mathrm{NS}$ & $0,37 \mathrm{NS}$ & $0,98 \mathrm{NS}$ & $0,22 \mathrm{NS}$ \\
\hline $\mathrm{T} 1$ vs $\mathrm{T} 2$ e $\mathrm{T} 3$ & $0,44 \mathrm{NS}$ & $0,16 \mathrm{NS}$ & $0,68 \mathrm{NS}$ & $0,00 \mathrm{NS}$ & $0,95 \mathrm{NS}$ \\
\hline T2 vs T3 & $0,86 \mathrm{NS}$ & $0,11 \mathrm{NS}$ & $0,07 \mathrm{NS}$ & $1,96 \mathrm{NS}$ & $0,52 \mathrm{NS}$ \\
\hline \multirow[t]{2}{*}{ CV $(\%)$} & 3,24 & 3,12 & 3,49 & 3,18 & 2,82 \\
\hline & \multicolumn{5}{|c|}{$\begin{array}{l}\text { Peso dos ovos }(\mathrm{g}) \\
\text { Egg weight }\end{array}$} \\
\hline $\mathrm{T} 1$ & 61,14 & 62,87 & 64,05 & 65,26 & 63,30 \\
\hline $\mathrm{T} 2$ & 60,29 & 61,74 & 62,93 & 64,49 & 62,36 \\
\hline T3 & 60,68 & 61,77 & 62,94 & 64,09 & 62,37 \\
\hline $\mathrm{F}$ & $2,66 \mathrm{NS}$ & $5,13 *$ & $5,30^{*}$ & $4,81^{*}$ & $5,11 *$ \\
\hline $\mathrm{T} 1$ vs T2 e T3 & $4,21 \mathrm{NS}$ & $10,25 * *$ & $10,61 * *$ & $8,49 *$ & $10,23 * *$ \\
\hline T2 vs T3 & $0,32 \mathrm{NS}$ & $0,00 \mathrm{NS}$ & $0,00 \mathrm{NS}$ & $1,12 \mathrm{NS}$ & $0,00 \mathrm{NS}$ \\
\hline \multirow[t]{2}{*}{$\mathrm{CV}(\%)$} & 0,96 & 1,02 & 0,98 & 0,94 & 0,88 \\
\hline & \multicolumn{5}{|c|}{$\begin{array}{c}\text { Massa de ovos (g/ave/dia) } \\
\text { Egg mass (g/bird/day) }\end{array}$} \\
\hline $\mathrm{T} 1$ & 52,59 & 54,16 & 53,16 & 50,92 & 52,71 \\
\hline $\mathrm{T} 2$ & 51,96 & 53,36 & 51,55 & 49,62 & 51,62 \\
\hline $\mathrm{T} 3$ & 53,45 & 53,75 & 51,29 & 50,73 & 52,31 \\
\hline $\mathrm{F}$ & $2,66 \mathrm{NS}$ & $0,32 \mathrm{NS}$ & 2,07NS & $1,35 \mathrm{NS}$ & $0,96 \mathrm{NS}$ \\
\hline T1 vs T2 e T3 & $0,91 \mathrm{NS}$ & $0,49 \mathrm{NS}$ & $4,07 \mathrm{NS}$ & $0,33 \mathrm{NS}$ & $0,30 \mathrm{NS}$ \\
\hline T2 vs T3 & $1,97 \mathrm{NS}$ & $0,15 \mathrm{NS}$ & $0,07 \mathrm{NS}$ & $0,22 \mathrm{NS}$ & $0,41 \mathrm{NS}$ \\
\hline $\mathrm{CV}(\%)$ & 3,19 & 2,91 & 3,04 & 2,68 & 2,39 \\
\hline
\end{tabular}

$\mathrm{NS}=$ não significativo, ${ }^{*}=$ significativo $\mathrm{P}<0,05,{ }^{*}=$ significativo $\mathrm{P}<0,01$.

$N S=$ not significant,${ }^{*}=$ significant $P<.05,{ }^{* *}=$ significant $P<.01$.

R. Bras. Zootec., v.31, n.3, p.1193-1203, 2002 
proteína por dia para reprodutoras pesadas no período de 36 a 52 semanas de idade, verificou que não houve diferenças na produção de ovos. O mesmo foi encontrado por Pearson \& Herron (1981) quando forneceram níveis de 19,4 a 26,9 g.

Embora a maior exigência de proteína bruta (66$67 \%$ ) tenha sido para produção de ovos, esta variável não teve diferença significativa entre os tratamentos. No entanto, o peso do ovo apresentou diferenças significativas para a maioria dos períodos estudados, conforme mostra a Tabela 6 .

Lopez \& Leeson (1995a) encontraram resultados similares quando forneceram menores quantidades de proteína na dietas de reprodutoras pesadas. As aves que consumiram ração com $10 \%$ de proteína bruta, consumo médio de $16 \mathrm{~g}$ de proteína/dia, tiveram pesos dos ovos inferiores.

Por outro lado, Pearson \& Herron $(1981,1982)$ não encontraram efeito significativo quanto ao peso dos ovos quando forneceram diferentes níveis de proteína (16,40 a $27,1 \mathrm{~g} /$ ave/dia) para aves reprodutoras pesadas durante todo período produtivo. Vale salientar que os autores também suplementaram as rações experimentais, quando necessário, com aminoácidos sintéticos, e as rações não foram formuladas somente à base de milho e farelo de soja, o que pode ter influenciado os resultados.

Couto (1988) encontrou que um fornecimento de $18 \mathrm{~g} /$ dia de proteína afetou o peso dos ovos quando comparados àqueles em que as aves ingeriram 20, 22 e $24 \mathrm{~g} /$ dia. Wilson \& Harms (1984), realizando experimentos com aves reprodutoras pesadas, encontraram que o nível de 20,6 g de proteína/dia foi suficiente para atender as exigências das aves.

Os resultados obtidos no presente trabalho estão de acordo com Waldroup et al. (1976), Pearson \& Herron (1981), Spratt \& Leeson (1987), segundo os quais o fornecimento de 18 a $20 \mathrm{~g} /$ dia parece atender as necessidades dos aminoácidos essenciais, porém níveis mais elevados ( $23 \mathrm{~g} / \mathrm{dia})$ podem ser necessários durante o período de alta produtividade para obtenção de máximo crescimento da massa do ovo.

Os tratamentos não afetaram significativamente a conversão alimentar, por outro lado, a equação testada proporcionou melhores resultados quanto à eficiência protéica (Tabela 7), uma vez que os consumos de proteína proporcionados pela equação foram menores e as produções não foram alteradas. Couto (1988) também não verificou influencia da ingestão de proteína na conversão alimentar quando forneceu os níveis de 18, 20, 22 e 24 g de proteína bruta por dia para reprodutoras pesadas.

Tabela 7 - Médias da conversão alimentar ( $g$ ração:g ovos) e eficiência protéica ( $g$ ração :g ovos ) das aves Table 7 - Means of feed conversion ( $g$ ration:g egg) and protein efficiency (g ration:g egg) in birds

\begin{tabular}{|c|c|c|c|c|c|}
\hline \multirow[t]{2}{*}{$\begin{array}{l}\text { Tratamentos } \\
\text { Treatments }\end{array}$} & \multicolumn{5}{|c|}{$\begin{array}{l}\text { Períodos (semanas) } \\
\text { Periods (weeks) }\end{array}$} \\
\hline & $(31-34)$ & $(35-38)$ & $(39-42)$ & $(43-46)$ & $(31-46)$ \\
\hline & \multicolumn{5}{|c|}{$\begin{array}{c}\text { Conversão alimentar }(\mathrm{g}: \mathrm{g}) \\
\text { Feed conversion }\end{array}$} \\
\hline $\mathrm{T} 1$ & 3,036 & 2,947 & 2,992 & 3,073 & 3,011 \\
\hline $\mathrm{T} 2$ & 3,026 & 3,001 & 3,094 & 3,158 & 3,067 \\
\hline $\mathrm{T} 3$ & 2,956 & 2,972 & 3,102 & 3,083 & 3,026 \\
\hline $\mathrm{F}$ & $1,00 \mathrm{NS}$ & $0,47 \mathrm{NS}$ & $1,93 \mathrm{NS}$ & $1,58 \mathrm{NS}$ & $0,81 \mathrm{NS}$ \\
\hline $\mathrm{T} 1$ vs $\mathrm{T} 2$ e $\mathrm{T} 3$ & $0,72 \mathrm{NS}$ & $0,67 \mathrm{NS}$ & $3,85 \mathrm{NS}$ & $1,10 \mathrm{NS}$ & $0,83 \mathrm{NS}$ \\
\hline $\mathrm{T} 2$ vs T3 & $1,28 \mathrm{NS}$ & $0,27 \mathrm{NS}$ & $0,02 \mathrm{NS}$ & $2,06 \mathrm{NS}$ & $0,79 \mathrm{NS}$ \\
\hline \multirow[t]{2}{*}{$\mathrm{CV}(\%)$} & 3,21 & 2,95 & 3,21 & 2,67 & 2,39 \\
\hline & \multicolumn{5}{|c|}{$\begin{array}{c}\text { Eficiência protéica (g:g) } \\
\text { Protein efficiency }\end{array}$} \\
\hline $\mathrm{T} 1$ & 0,455 & 0,442 & 0,449 & 0,461 & 0,452 \\
\hline $\mathrm{T} 2$ & 0,414 & 0,398 & 0,404 & 0,406 & 0,405 \\
\hline $\mathrm{T} 3$ & 0,406 & 0,390 & 0,396 & 0,393 & 0,396 \\
\hline $\mathrm{F}$ & $23,78^{* *}$ & $25,60^{* *}$ & $27,71 * *$ & $63,25 * *$ & $51,82 * *$ \\
\hline $\mathrm{T} 1$ vs T2 e T3 & $46,43 * *$ & $50,27 * *$ & $54,47 * *$ & $122,52 * *$ & $101,29 * *$ \\
\hline $\mathrm{T} 2$ vs T3 & $1,12 \mathrm{NS}$ & $0,93 \mathrm{NS}$ & $1,08 \mathrm{NS}$ & $3,97 \mathrm{NS}$ & $2,36 \mathrm{NS}$ \\
\hline CV $(\%)$ & 2,88 & 3,04 & 2,92 & 2,42 & 2,22 \\
\hline
\end{tabular}

NS = não significativo, ${ }^{* *}=$ significativo $\mathrm{P}<0,01\left(N S=\right.$ not significant, ${ }^{* *}=$ significant $\left.P<.01\right)$. 
Os diferentes tratamentos não influenciaram o peso corporal (Tabela 8). Por outro lado, a composição química corporal das aves foi afetada. As aves submetidas aos tratamentos em que a equação foi avaliada diferiram entre si quanto a quantidade (g) de cinzas e gordura (Tabela 9). Lopez \& Leeson (1995a) observaram que dietas com $16 \%$ de $\mathrm{PB}$ ( 24 a $25 \mathrm{gPB} /$ ave/dia) levaram a maior ganho de peso, sendo significativamente mais elevado em gordura, quando comparadas com as aves que consumiram rações com 10, 12 e 14\% de PB (15-16, 18-19, 21-22,5 g/ave/dia, respectivamente) refletindo assim na taxa de eclosão.

Tabela 8 - Médias de peso corporal das aves $(\mathrm{g})$ às 34 , 3842 e 46 semanas de idade (final de cada período)

Table 8 - Body weight means $(\mathrm{g})$ of birds at 34, 38, 42 e 46 weeks of age (at the end of each period)

\begin{tabular}{lcccc}
\hline $\begin{array}{l}\text { Tratamentos } \\
\text { Treatments }\end{array}$ & \multicolumn{4}{c}{$\begin{array}{c}\text { Idade (semanas) } \\
\text { Age (Weeks) }\end{array}$} \\
\cline { 2 - 5 } & 34 & 38 & 42 & 46 \\
\hline T1 & 3644 & 3690 & 3804 & 3944 \\
T2 & 3598 & 3649 & 3779 & 3965 \\
T3 & 3585 & 3676 & 3790 & 3996 \\
F & $1,80 \mathrm{NS}$ & $1,06 \mathrm{NS}$ & $0,12 \mathrm{NS}$ & $1,52 \mathrm{NS}$ \\
T1 vs T2 e T3 & $3,43 \mathrm{NS}$ & $1,23 \mathrm{NS}$ & $0,19 \mathrm{NS}$ & $2,06 \mathrm{NS}$ \\
T2 vs T3 & $0,17 \mathrm{NS}$ & $0,90 \mathrm{NS}$ & $0,05 \mathrm{NS}$ & $0,99 \mathrm{NS}$ \\
CV $(\%)$ & 1,41 & 1,24 & 2,09 & 1,24 \\
\hline NS
\end{tabular}

NS = não significativo ( $N S$ = not significant).
Quanto ao desempenho reprodutivo, apresentado na Tabela 10, não foram encontradas diferenças significativas na eclodibilidade, taxa de eclosão e fertilidade, indicando que o baixo nível de proteína preconizado pela equação não afetou os parâmetros reprodutivos, mas proporcionou menores pesos dos pintinhos, conseqüência dos menores pesos dos ovos.

Foram encontradas diferenças significativas no peso dos pintinhos, sendo maiores quando foram incubados os ovos produzidos durante o pico de postura. Os pintinhos apresentaram diferenças no peso de aproximadamente 1 a $1,2 \%$, seguido da segunda incubação, com diferenças de 0,50 a $0,80 \%$ para as aves alimentadas de acordo com os tratamentos da equação em relação ao tratamento controle. Lopez e Leeson (1995b) obtiveram resultados similares quando alimentaram aves reprodutoras com dietas de baixa proteína às 30 semanas ( 16 e $19 \mathrm{~g}$ vs 22,5 e $25,5 \mathrm{~g}$ de proteína/dia) e às 50 semanas de idade ( $15 \mathrm{~g}$ vs 18, 21 e $24 \mathrm{~g}$ de proteína/dia). Couto (1988) encontrou que aves consumindo $18 \mathrm{~g}$ de proteína por dia produziram pintos com pesos menores $(43,2 \mathrm{~g})$ quando comparados com os pintos provenientes das aves que ingeriram 20,22 e $24 \mathrm{~g}$ de proteína $(45,3$; 44,5 a 45,8 g). O mesmo comportamento foi encontrado por Wilson \& Harms (1984) e Spratt \& Leeson (1987).

A redução de proteína na dieta pode levar a resultados satisfatórios quando suplementados com aminoácidos sintéticos (NRC, 1994), o que foi constatado por Bornstein \& Hurwitz (1979) e Lopez \& Leeson (1995a, b).

Tabela 9 - Médias da composição química corporal das aves abatidas no final do período experimental às 46 semanas de idade

Table 9 - Means of body chemistry composition for slaughter birds at the end of experimental period at 46 weeks of age

\begin{tabular}{|c|c|c|c|c|c|c|c|c|}
\hline \multirow{4}{*}{$\begin{array}{l}\text { Tratamentos } \\
\text { Treatment }\end{array}$} & \multicolumn{8}{|c|}{$\begin{array}{c}\text { Composição corporal }^{1} \\
\text { Body composition }\end{array}$} \\
\hline & \multirow{2}{*}{\multicolumn{2}{|c|}{$\begin{array}{l}\text { Água } \\
\text { Water }\end{array}$}} & \multirow{2}{*}{\multicolumn{2}{|c|}{$\begin{array}{c}\text { Cinzas } \\
\text { Ash }\end{array}$}} & \multirow{2}{*}{\multicolumn{2}{|c|}{$\begin{array}{c}\text { Gordura } \\
\text { Fat }\end{array}$}} & \multirow{2}{*}{\multicolumn{2}{|c|}{$\begin{array}{l}\text { Proteína } \\
\text { Protein }\end{array}$}} \\
\hline & & & & & & & & \\
\hline & $\%$ & $\mathrm{~g}$ & $\%$ & $\mathrm{~g}$ & $\%$ & $\mathrm{~g}$ & $\%$ & $\mathrm{~g}$ \\
\hline $\mathrm{T} 1$ & 56,8 & $2.083,4$ & 3,5 & 128,5 & 19,3 & 709,3 & 17,1 & 627,2 \\
\hline $\mathrm{T} 2$ & 57,1 & $2.084,2$ & 3,4 & 124,5 & 19,5 & 710,5 & 16,6 & 604,8 \\
\hline $\mathrm{T} 3$ & 54,8 & $2.028,9$ & 3,8 & 140,1 & 21,3 & 789,2 & 17,1 & 632,9 \\
\hline $\mathrm{F}$ & $2,35 \mathrm{NS}$ & $0,88 \mathrm{NS}$ & $2,35 \mathrm{NS}$ & $3,02 \mathrm{NS}$ & $3,22 \mathrm{NS}$ & $3,54 \mathrm{NS}$ & $0,58 \mathrm{NS}$ & $0,88 \mathrm{NS}$ \\
\hline $\mathrm{T} 1 \mathrm{vs} \mathrm{T} 2$ e $\mathrm{T} 3$ & $0,68 \mathrm{NS}$ & $0,42 \mathrm{NS}$ & $0,39 \mathrm{NS}$ & $0,45 \mathrm{NS}$ & $1,96 \mathrm{NS}$ & $1,85 \mathrm{NS}$ & $0,26 \mathrm{NS}$ & $0,18 \mathrm{NS}$ \\
\hline T2 vs T3 & $4,03 \mathrm{NS}$ & $1,34 \mathrm{NS}$ & $4,31 \mathrm{NS}$ & $5,59^{*}$ & $4,49 \mathrm{NS}$ & $5,23 *$ & $0,89 \mathrm{NS}$ & $1,57 \mathrm{NS}$ \\
\hline CV $(\%)$ & 3,24 & 3,65 & 8,07 & 7,96 & 5,28 & 7,39 & 5,28 & 5,71 \\
\hline
\end{tabular}

${ }^{1}$ Composição corporal de aves depenadas submetidas a jejum de 24 horas (Body composition of defeathered birds submitted to a 24 hour fast). NS = não significativo, ${ }^{*}=$ Significativo $\mathrm{P}<0,05$ (NS = not significant, ${ }^{*}=$ significant $\left.P<.05\right)$. 


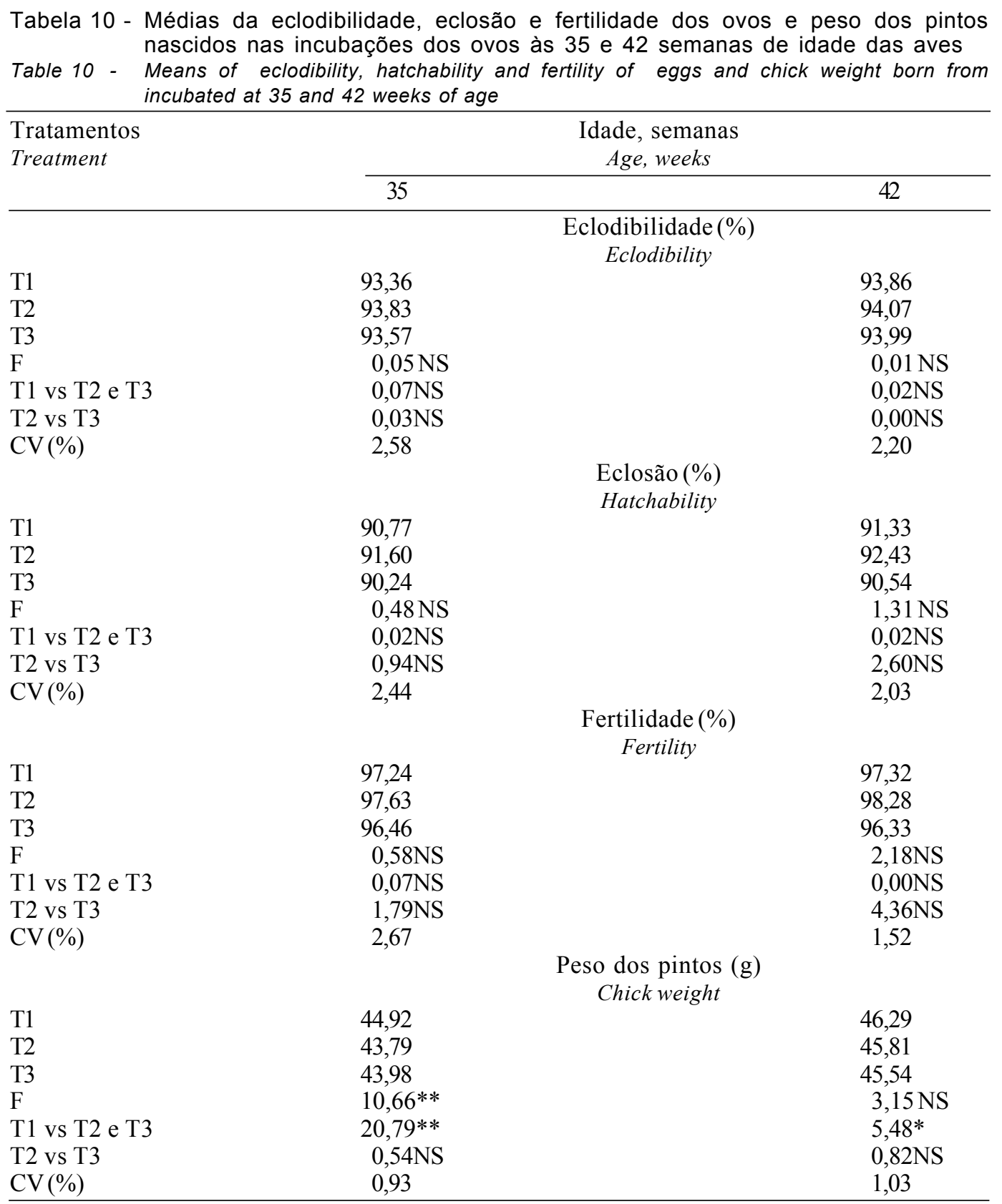

NS = não significativo, ${ }^{*}=$ Significativo $\mathrm{P}<0,05,{ }^{* *}=$ significativo $\mathrm{P}<0,01$

$N S=$ not significant, ${ }^{*}=$ significant $P<.05,{ }^{* *}=$ significant $P<.01$.

Na Tabela 11 estão apresentados os dados de ganho de peso e produção de ovos observados e preditos, respectivamente, dos tratamentos experimentais. Observa-se que os melhores resultados quanto ao ganho de peso observado em relação ao previsto durante os três primeiros períodos avaliados foram do tratamento controle (T1) que apresentou menores resultados na soma do quadrado dos desvios (SQDv), entretanto no quarto período o melhor resultado foi encontrado no tratamento T2 e conseqüentemente refletindo no período total.
Observa-se que com o passar da idade os resultados das SQDvs se elevam devido aos maiores ganhos de peso das aves em todos os tratamentos quando comparado com o ganho de peso predito. Este comportamento foi provocado pelo elevado consumo de energia.

Quanto à produção de massa de ovos, os resultados foram satisfatórios, entretanto com melhores ajustes para o tratamento controle, que apresentou menores valores da SQDv. Essas diferenças podem ser explicadas pelos menores pesos dos ovos produzidos 
Tabela 11 - Médias para ganho de peso $(\mathrm{g})$ e produção de massa de ovos ( $\mathrm{g}$ ) observado e predito semanalmente e durante cada período e as diferenças entre os valores observado e predito dos tratamentos experimentais

Table 11 - Means for weight gain $(g)$ and egg mass production ( $g$ ) observed and predicted weekly during the period and the difference between the observed and predicted values

\begin{tabular}{|c|c|c|c|c|c|c|c|c|c|}
\hline $\begin{array}{l}\text { Períodos } \\
\text { Periods }\end{array}$ & $\begin{array}{c}\text { Idade } \\
\text { (semanas) } \\
\text { Age } \\
\text { (Weeks) }\end{array}$ & $\begin{array}{c}\text { GPP } \\
\text { (g/dia) } \\
\text { GPP } \\
\text { g/bird/day }\end{array}$ & $\begin{array}{c}\text { GPO } \\
\text { (g/dia) } \\
\text { GPO } \\
\text { g/bird/day }\end{array}$ & $\begin{array}{l}\text { Diferença } \\
(\mathrm{P}-\mathrm{O}) \\
\text { Difference } \\
(P-O)\end{array}$ & $\begin{array}{c}\text { SQDv }^{1} \\
S S D\end{array}$ & $\begin{array}{c}\text { MOP } \\
\text { (g/dia) } \\
P M E \\
\text { (g/bird/day) }\end{array}$ & $\begin{array}{c}\text { MOO } \\
\text { (g/dia) } \\
M E O \\
\text { (g/bird/day) }\end{array}$ & $\begin{array}{c}\text { Diferenças } \\
(\mathrm{P}-\mathrm{O}) \\
\text { Difference } \\
(\mathrm{P}-\mathrm{O})\end{array}$ & $\begin{array}{c}\text { SQDv }^{1} \\
S S D\end{array}$ \\
\hline \multicolumn{10}{|c|}{$\begin{array}{l}\mathrm{T} 1 \text { - Controle } \\
\text { Standard }\end{array}$} \\
\hline 1 & $31-34$ & 5,00 & 3,77 & $-1,23$ & 242,52 & 52,92 & 52,59 & $-0,33$ & 60,90 \\
\hline 2 & $35-38$ & 2,49 & 1,66 & $-0,83$ & 330,26 & 54,22 & 54,16 & $-0,06$ & 97,76 \\
\hline 3 & $39-42$ & 1,70 & 4,06 & 2,35 & 532,60 & 53,34 & 53,16 & $-0,18$ & 75,28 \\
\hline 4 & $43-46$ & 1,29 & 4,95 & 3,66 & 2555,13 & 51,07 & 50,92 & $-0,15$ & 76,07 \\
\hline Total* & $31-46$ & 3,08 & 3,61 & 0,53 & 3666,52 & 52,89 & 52,71 & $-0,18$ & 310,00 \\
\hline \multicolumn{10}{|l|}{ Total } \\
\hline 1 & $31-34$ & 5,00 & 2,46 & $-2,55$ & 454,45 & 52,92 & 51,96 & $-0,96$ & 127,68 \\
\hline 2 & $35-38$ & 2,49 & 1,80 & $-0,69$ & 528,09 & 54,22 & 53,37 & $-0,85$ & 129,20 \\
\hline 3 & $39-42$ & 1,70 & 4,64 & 2,94 & 735,46 & 53,40 & 51,55 & $-1,85$ & 233,82 \\
\hline 4 & $43-46$ & 1,30 & 6,41 & 5,11 & 1617,98 & 51,07 & 49,62 & $-1,44$ & 152,73 \\
\hline Total* & $31-46$ & 3,08 & 3,83 & 0,74 & 3336,27 & 52,90 & 51,62 & $-1,28$ & 643,43 \\
\hline \multirow{2}{*}{\multicolumn{10}{|c|}{ Total }} \\
\hline & & & & & & & & & \\
\hline 1 & $31-34$ & 4,96 & 2,96 & $-2,00$ & 335,40 & 53,96 & 53,44 & $-0,52$ & 106,69 \\
\hline 2 & $35-38$ & 2,45 & 3,24 & 0,79 & 550,33 & 53,97 & 53,75 & $-0,21$ & 83,60 \\
\hline 3 & $39-42$ & 1,70 & 2,91 & 1,22 & 1460,69 & 51,74 & 51,29 & $-0,45$ & 141,81 \\
\hline 4 & $43-46$ & 1,30 & 7,37 & 6,07 & 3205,64 & 50,45 & 50,74 & 0,28 & 80,64 \\
\hline Total* & $31-46$ & 3,34 & 4,41 & 1,07 & 5552,06 & 52,53 & 52,30 & $-0,23$ & 412,74 \\
\hline
\end{tabular}

* Valores calculados considerando o ganho de peso inicial e final observado (GPO) e predito (GPP) e a massa de ovos observada (MOO) e prevista (MOP)

Calculated values considering initial and final weight gain observed (GPO) and predicted, and egg mass observed (EMO) and predicted (MOP)

1 Soma dos Quadrados dos desvios (Square sum of deviations).

pelas aves submetidas ao teste da equação (T2 e T3).

O nível de proteína proporcionado pela equação foi suficiente para atender de forma satisfatória as exigências mínimas de proteína bruta para produção de ovos e pintos, por outro lado, durante o período de maior produção (pico de produção) o nível de proteína preconizado pela equação não foi suficiente para atender as exigências mínimas dos aminoácidos não suplementados, influenciando o peso dos pintos.

Segundo Harms (1992), existe dificuldade em se dissociar os efeitos da suplementação da proteína dos efeitos dos aminoácidos limitantes, especialmente metionina, lisina e triptofano.

Com intuito de diminuir o nível de poluição ambiental, pelo excesso de nitrogênio excretado, é possível o fornecimento de proteína bruta às aves reprodutoras pesadas por intermédio da equação determinada, sem, contudo, afetar o desempenho produtivo, entretanto, podendo afetar o peso dos ovos, que, segundo Scholoffel et al. (1988), tem efeito significativo no peso inicial dos pintinhos e seu desempenho produtivo.

\section{Conclusões}

A equação de predição não forneceu a quantidade mínima de proteína bruta para atender as exigências dos aminoácidos não suplementados na dieta, principalmente no período do pico de postura, em que os pintos apresentaram menor peso vivo.

\section{Agradecimento}

À Fundação de Amparo à Pesquisa do Estado de São Paulo (FAPESP), pelo apoio financeiro; à Granja Rezende, pela doação das aves; e à AJINOMOTO, pelos aminoácidos sintéticos L-triptofano e L-arginina. 


\section{Literatura Citada}

ASSOCIATION OF OFFICIAL ANALYTICAL CHEMISTS AOAC. Official methods of analysis. 16.ed. Washington. D.C.: 1990. 1094p.

BORNSTEIN, S.; HURWITZ, S.; LEV, Y. The amino acid and energy requirements of broiler breeder hens. Poultry Science, v.58, n.1, p.104-116, 1979.

COUTO, H.P. Exigências nutricionais de proteína para galinhas reprodutoras de corte. Viçosa, MG: Universidade Federal de Viçosa, 1988. 47p. Dissertação (Mestrado em Zootecnia) - Universidade Federal de Viçosa, 1988.

HARMS, R.H. A determination of the order limitation of amino acids in a broiler breeder diet. Journal of Applied Poultry Research, v.1, p.410-414, 1992.

HURWITZ, L. BORNSTEIN, S. The protein and amino acid requirements of laying hens: suggested models for calculation. Poultry Science, v.52, n.3, p.1124-1134, 1973.

INTITUTE NATIONAL DE LA RECHEARCHE AGRONOMIQUE. L'alimentacion des animaux monogastriques. Paris: 1984. 279p.

LEESON, S.; SUMMERS, J.D. Broilers breeder production. Guelph: University Books, 2000. 334p.

LOPEZ, G.; LEESON, S. Response of broiler breeders to lowprotein diets. 1. Adults breeder performance. Poultry Science, v.74, n.4, p.685-695, 1995a.

LOPEZ, G.; LEESON, S. Response of broiler breeders to lowprotein diets. 2. Offspring performance. Poultry Science, v.74, n.4, p.696-701, 1995b.

NATIONAL RESEARCH COUNCIL - NRC. Committee on Animal Nutrition. Subcommittee on Poultry Nutrition. Nutrient requirements of poultry. 9.ed. Washington, D.C.: National Academy of Sciences, 1994. 155p.

PEARSON, R.A.; HERRON, K.M. Effects of energy and protein allowance during lay on the reproductive performance of broiler breeder. British Poultry Science, v.22, n.2, p.227-239, 1981.

PEARSON, R.A.; HERRON, K.M. Relationship between energy and protein intakes and laying characteristics in individuallycaged broiler breeder hens. British Poultry Science, v.23, n.1, p.171-181, 1982.
RABELLO, C. B. V. Equações de predição das exigências de energia e proteína para reprodutoras pesadas na fase de produção. Jaboticabal: Universidade Estadual Paulista, 2001. 121 p. Tese (Doutorado em Zootecnia) - Universidade Estadual Paulista, 2001.

SANTOMÁ, G. Necessidades protéicas de las gallinas ponedoras. In: DE BLAS, C.; MATEOS, G.G (Eds.) Nutricion y alimentación de gallinas ponedoras. Madrid: Mundi-Prensa, 1991. p.71-114.

SAS INSTITUTE. SAS Guide Statistics. Version 6. 12.ed. Cary: 1996.

SCHLOFFEL, H.; JEROCH, J.H.; GEBHARDT, G. Influence of the energy and protein supply broiler hens on their laying performance, live weight development reproductive performance and the growth of broiler chickens. Archives Animal Nutrition, v.38, p.493, 1988.

SCOTT, M.L.; NESHEIM, M.C.; YOUNG, R.J. Nutrition of the chicken. 3.ed. Ithaca: M.L. Scott, 1982. 562p.

SPRATT, R.S.; LEENSON, S. Effect of protein and energy intake of broiler breeder hens on performance of broiler chicken offspring. Poultry Science, v.66, n.6, p.1489-1494, 1987.

WALDROUP, P.W.; HAZEN, K.R.; BUSSEL, W.D. et al. Studies on the daily protein and amino acid needs of broiler breeders hens. Poultry Science, v.55, n.9, p.2342-2347, 1976.

WILSON, H.R.; HARMS, R.H. Evaluation of nutrient specifications for broilers breeders. Poultry Science, v.63, n.7, p.1400-1406, 1984. 